\title{
Liberdade de expressão comercial como estratégia corporativa do setor publicitário brasileiro ${ }^{1}$
}

\section{Glicia Maria Pontes Bezerra}

\section{Resumo}

0 objetivo deste artigo é investigar as origens

do conceito "liberdade de expressão comercial" e analisar como ele passou a ser adotado pelo setor publicitário brasileiro a partir dos anos 1990. A pesquisa foi realizada a partir da coleta de documentos e entrevistas que auxiliaram na reconstrução do histórico das entidades do setor, bem como das disputas em torno da regulamentação da publicidade, e permitiu a percepção das posições discursivas contrárias às iniciativas regulatórias que visavam a um maior controle da publicidade no país. A análise constatou que 0 atual discurso em defesa da liberdade de expressão comercial é uma síntese fundamentada em três matrizes: defesa das liberdades, defesa da autorregulamentação e defesa da atividade publicitária.

\section{Palavras-Chave}

Liberdade de expressão. Publicidade. Regulamentação. Discurso.

\section{A livre iniciativa como causa do setor publicitário brasileiro}

Por ser um ramo ainda em consolidação no Brasil no final da década de 1970, era constante a necessidade de justificativa em relação à importância da publicidade para a economia brasileira, evitando, assim, os julgamentos de que seria um gasto supérfluo, que encarecia o preço final dos produtos ou divulgava informações ilusórias. Portanto, era preciso convencer tanto os industriais e empresários brasileiros a investir em propaganda como as audiências em geral sobre a credibilidade da informação publicitária, e, para tanto, as entidades criaram campanhas e se posicionaram firmemente contrárias às críticas e às primeiras iniciativas de regulação do conteúdo da publicidade surgidas nessa década, quando, por um lado, a ditadura militar propunha um controle moralista do conteúdo veiculado nas mídias e, por outro lado, alguns movimentos começavam a discutir a defesa do consumidor no Brasil.

Nesse sentido, inspirada por ideais liberais, iniciou-se, em 1976, a campanha do Movimento 
Nacional pela Livre Iniciativa (MNLI), coordenada por Héctor Brenner, publicitário argentino radicado no Brasil. 0 intuito era fortalecer o modelo de desenvolvimento capitalista baseado na economia de mercado, evitando ingerências externas, como regulamentações, controle de preços e legislações que pudessem alterar o cenário econômico, e visando "promover os princípios constitucionais de liberdade de iniciativa, livre economia de mercado orientada socialmente, essencialidade da empresa privada e caráter suplementar do Estado na organização e exploração das atividades econômicas" (CORRÊA, 2008, p. 15). Na carta de lançamento do movimento, Brenner afirma que o mesmo nasce em um contexto de ameaça à livre iniciativa, o que torna 0 sistema "perigosamente vulnerável a outras correntes de pensamento ideológico" (CORRÊA, 2008, p.36). Com a abertura do espaço público, sinalizada pelos ideais democráticos que pressionavam por uma distensão do regime autoritário, a intervenção progressista do Estado passava a ser uma possibilidade concreta e, por conseguinte, uma ameaça aos defensores da livre iniciativa contrários a qualquer tipo de intervenção.

Além do cerceamento das liberdades, que era cada vez mais contestado, o regime dava sinais de fracasso econômico: 0 crescimento manteve altas taxas, mas não resultou em igualdade social e, apesar de ter um papel indispensável no desenvolvimento econômico, o Estado não demonstrou ter um projeto nacional (FIORI, 2003, p. 194). Para Fiori (2003, p. 23), as críticas ao Estado nesse período confundiam-se "com a luta pela redemocratização" e se originavam de diferentes visões sobre o papel do Estado. 0 autor identifica duas linhas de pensamento predominantes naquele momento: a existência da ideologia neoliberal, que propunha a "desestatização da economia e a reafirmação do indivíduo consumidor" (FIORI, 2003, p. 24), em oposição ao pensamento progressista que ia do "keynesianismo de esquerda ao socialismo" (id.) e defendia a presença do Estado.

Nesse contexto, a posição discursiva assumida pelo setor publicitário foi a defesa da livre iniciativa como o caminho correto para "salvar a economia brasileira" (CORRÊA, 2008, p. 19) e como contraponto às regulações surgidas nesse período em âmbito estatal, com o objetivo de normatizar a propaganda. Como resposta a estas, 0 setor publicitário fortaleceu o sentimento de que era urgente a criação de um código de autorregulamentação da atividade, com o papel de regular a publicidade no Brasil, a partir de normas elaboradas e gerenciadas pelos próprios agentes do setor para disciplinar 0 conteúdo dos anúncios. A liberdade de iniciativa e a não interferência do Estado na regulação da propaganda foram, assim, acolhidas pelo setor publicitário, e a criação do Código Brasileiro 
de Autorregulamentação Publicitária, em 1978, consolidou essa posição discursiva como estratégica para o novo momento do país. É esse 0 argumento fundante da formação ideológica e discursiva adotada pelo setor publicitário no final da década de 1970 e que, em certa medida, permanece ao incorporar o discurso neoliberal que põe mercado e liberdade como equivalentes, ao mesmo tempo em que aponta o Estado como esfera oposta ao exercício da liberdade.

\section{Da livre iniciativa à liberdade de expressão: um novo discurso para um novo momento}

A Assembleia Constituinte foi o primeiro momento mais intenso de embate direto, pós-criação do Conselho Nacional de Autorregulamentação Publicitária (Conar) - conselho criado para gerenciar o código de autorregulamentação aprovado em 1978 - entre o setor publicitário e esferas do Estado e da sociedade civil interessadas em regular os assuntos relativos à atividade publicitária. Durante os debates para elaboração da nova Carta Magna, o Conar foi cobrado pelos agentes do setor publicitário para aparecer como uma "entidade a serviço da sociedade", mostrando que a publicidade é uma atividade autorregulamentada no país e que seus profissionais atuam "responsavelmente", sendo submetidos a um código de ética². Os publicitários críticos à Constituição viam como "perigosa" a interferência do Estado na atividade publicitária e, portanto, consideraram importante contraporse à inclusão de restrições à propaganda no texto constitucional, que autorizaria essa intervenção estatal. Frente às proposições de novas regulações, o discurso de exaltação ao Conar e em defesa da autorregulamentação ganhou mais força e unidade dentro do setor publicitário: "É a coisa mais saudável que já aconteceu na propaganda brasileira, pois é uma forma inteligente de espantar o perigo da interferência do poder público na nossa atividade"3.

As mobilizações em torno da Constituinte foram resultado do processo de redemocratização e estavam vinculadas às ideias desenvolvimentistas que propunham reformas por meio de um "projeto de democratização social e política". Segundo Fiori (2003), essa influência é percebida no texto final, principalmente nos "capítulos relacionados com os direitos civis, sociais, políticos e econômicos da cidadania brasileira" (FIORI, 2003, p.13). Maria Hermínia Tavares de Almeida (1995, p. 180) afirma que o empresariado teve "dificuldade de formular propostas próprias" e de definir "uma agenda comum", o que resultou na sua derrota na "elaboração do capítulo social da nova Carta" (ALMEIDA, 1995, p. 180). Porém, mesmo assim, alguns artigos foram modificados a partir de pressão das classes proprietárias. 
A inclusão dos artigos relacionados à regulação da propaganda comercial no capítulo sobre Comunicação Social da Constituição Federal gerou protestos e inúmeras manifestações contra a "censura comercial" ${ }^{4}$ por parte dos empresários. A partir de um jogo que articulava contraditoriamente a censura praticada na ditadura com a regulação proposta no âmbito democrático, o setor publicitário equiparava os dois usos e afirmava que as tentativas de regulação poderiam pôr em xeque a liberdade das atividades comerciais, como a publicidade. À época da Constituinte, o setor pronunciou-se através de artigos na imprensa, debates nos meios especializados e, mais diretamente, por meio de lobby $^{5}$ no Congresso Nacional.

\section{Jornal Meio \& Mensagem destacava a união} alinhavada pela Associação Brasileira de Anunciantes (ABA), que publicou em seu jornal um editorial conclamando anunciantes, agências, veículos e fornecedores para defenderem "seus interesses comuns" na Constituinte, tais como: "preservar algumas liberdades básicas para a democracia, a livre iniciativa e a indústria publicitária: a liberdade de empreender, a liberdade de comprar e vender, a liberdade de anunciar e a liberdade de relacionamento empresarial e setorial"'.
Assim como a utilização do termo "sociedade civil", a adoção do conceito de liberdade como central nessa ordem discursiva remonta a uma "confluência perversa", tal qual definiu Dagnino (2004b). Essa análise converge com a definição de interdiscurso em Courtine (1981, p. 54), que percebe esse tipo de uso como "uma articulação contraditória de formações discursivas que se referem a formações ideológicas antagonistas".

A causa do setor publicitário naquele momento era resumida em matéria do Meio \& Mensagem sobre a propaganda na Constituinte: "A questão que está em jogo é a liberdade de anunciar"? A transformação dessa estratégia discursiva - defesa da liberdade de anunciar - para a posterior que se baseia na defesa da liberdade de expressão se deu, principalmente, por meio de influência internacional. Em reunião da World Federation of Advertisers (WFA) no ano de 1987, o então presidente mundial da organização não governamental Artigo 19, que atua globalmente na defesa da liberdade de expressão, Kevin Boyle, igualou a liberdade de anunciar ao livre direito de se expressar e, em síntese, defendeu: "free speech (livre expressão); free choice (livre escolha); free market (livre mercado)"8. Vinculou, pois, 0 direito de se expressar ao ideal do livre mercado e da livre escolha. Essa equiparação, proclamada

A abominável censura comercial. Jornal do Brasil, Rio de Janeiro, p. 11, 09 set. 1987.

Lobby diminui efeitos do pacote sobre a propaganda. Meio \& Mensagem, São Paulo, nº 186, capa, Dez. 1985.

ABA prega união para Constituinte. Meio \& Mensagem, São Paulo, nº 241, p. 14, jan. 1987.

Liberdade para anunciar. Meio \& Mensagem, São Paulo, nº 260, editorial, jun.1987.

Liberdade para anunciar. Meio \& Mensagem, São Paulo, nº 260, editorial, jun.1987. 
por várias outras entidades e lideranças do meio, passou a fazer parte da ordem do discurso do setor publicitário e da indústria da comunicação. É possível perceber nesse uso uma estratégia discursiva de ampliação do interesse particular do setor publicitário (liberdade de anunciar) para um interesse geral (liberdade de expressão).

Essa estratégia se fortaleceu ao longo dos anos 1990, chegando ao seu ápice no período de discussão sobre a restrição à publicidade de cigarro. Nesse período, a Associação Brasileira de Emissoras de Rádio e Televisão (ABERT) e o Conar fizeram uma campanha favorável à liberdade de expressão e defenderam que todo produto lícito tem 0 "direito constitucional de ser anunciado".

Esse momento lançou uma nova fase na argumentação em prol da autorregulamentação, desta vez marcada pela defesa da liberdade de expressão comercial, tendo como base principal os seguintes argumentos: 1) a contribuição da atividade publicitária para a economia, que consiste na existência de uma relação entre agência, veículo e anunciante que promove a ampliação do consumo e, logo, estimula 0 crescimento econômico e a geração de empregos. Toda essa engrenagem seria abalada com a proibição da veiculação de anúncios de cigarros em meios massivos; 2) a crítica à visão "paternalista" do Estado protetor, o qual entende 0 consumidor como inabilitado a avaliar os anúncios e suas mensagens, que se contrapõem à visão dos movimentos consumeristas que indicam a "vulnerabilidade" do consumidor, considerando-0 como a parte fraca na relação de consumo; 3) a defesa da publicidade como fonte de informação, em oposição à ideia de que, pelo caráter comercial da atividade, sua mensagem teria menos relevância social, além do seu valor cultural, por financiar os veículos de comunicação que, desta forma, podem propagar-se como independentes perante 0 poder público; 4) a ideia de que a publicidade pode ser considerada como uma das formas de manifestação de pensamento incluídas na proteção constitucional à liberdade de expressão, contrária, portanto, à visão de que deve ser submetida a normas restritivas pelo Estado.

Assim, mais do que considerar os efeitos negativos do consumo de produtos nocivos à saúde, 0 setor publicitário preocupou-se em defender o princípio da liberdade de anunciar, propondo que a interferência na atividade é inaceitável, mesmo que estejam em jogo assuntos de interesse da saúde pública. Percebe-se nessa posição discursiva algo apontado por Amorim (2013, p. 22) como prática da tradição liberal: a "sobreposição de opiniões e interesses particulares sobre as opiniões e interesses públicos".

\section{Liberdade de expressão comercial: os fundamentos do conceito}

As abordagens conflituosas que põem em oposição a defesa da liberdade de expressão e as regulações das comunicações já foram objeto de importantes trabalhos acadêmicos (LIMA, 2012; BLOTTA, 2012; AMORIM; GUIMARÃES, 2013). É essencial perceber 
o setor publicitário como parte importante dessa indústria da comunicação e os diálogos entre 0 setor publicitário, a imprensa e os demais setores industriais como fundados em discursos favoráveis à "liberdade de expressão comercial".

Em um ensaio sobre a democratização dos meios de comunicação de massa, o jurista e professor Fábio Konder Comparato (2000) traça um histórico das formas de liberdade de expressão que vai desde a democracia ateniense, passando pelo absolutismo e chegando ao capitalismo contemporâneo. Para o autor, em todas as sociedades, os "detentores do poder" buscam 0 "reconhecimento da sua legitimidade", que seria concretizada com a atuação de intelectuais alinhavados com as classes dominantes, os quais usariam o seu poder de convencimento para dar legitimidade ao regime em vigor. Com 0 desenvolvimento dos meios de comunicação no século XX, essa função propagadora ganhou proporções massivas, pois as mensagens por eles veiculadas passaram a atingir grandes escalas de público. Diante disso, Comparato (2000, p. 12) considera que as formas anteriores de expressão individual tornaram-se obsoletas em termos de efeitos para a formação de uma opinião pública favorável ou desfavorável ao sistema vigente.

A partir dessa análise e da compreensão sobre a lógica empresarial e capitalista praticada por esses meios, Comparato (2000) alega que há, por parte dos conglomerados de mídia, uma apropriação confusa do termo "liberdade de expressão" como sinônimo de liberdade de atuação corporativa. E defende que 0 caráter privado dos meios põe em questão 0 interesse público.

Nessa formulação, percebe-se uma visão oposta à adotada pelos grupos empresariais e por Jerry Kirkpatrick (1997) que entende 0 direito à liberdade de expressão como extensivo às corporações. Esse tipo de confusão ideológica foi apontada por Fredric Jameson como resultado de uma simplificação feita pelos ideólogos neoliberais, que, ao identificarem "liberdade política com a liberdade de mercado", na verdade, têm implícita a preocupação com a lucratividade, a qual pode ser ameaçada pela interferência do Estado (JAMESON, 2006, p. 221). Comparato (2000) se propõe a desmistificar esse uso liberal do direito à liberdade de expressão e indica que, muitas vezes, a esfera estatal, em todos os seus poderes, tem sido conivente com a oligopolização dos meios de comunicação, afinal, suas estruturas são dominadas ou sofrem pressões dos interesses privados.

Para Amorim e Guimarães (2013), há uma nítida oposição entre as apropriações feitas pela tradição liberal e pela tradição republicana em relação ao conceito de liberdade de expressão. A proposta dos autores é, portanto, discutir esse conceito, compreendendo-o como definição em aberto e em disputa. Amorim (2013b, p. 13) explica que o seu objetivo com essa discussão é expor "uma linguagem alternativa à linguagem 
liberal que se apresenta como hegemônica, buscando encerrar o debate como se os conceitos estivessem dados" (id.).

Ao discutir a formação da esfera pública burguesa, Habermas (2003) identificou contradições e disputas em torno de algumas visões majoritárias sobre a opinião pública, de um lado, a visão liberal, de outro, a visão socialdemocrata. 0 autor considerou que a disputa principal referia-se à forma de publicidade adotada, entendendo publicidade aqui como a função crítica exercida pela opinião pública (HABERMAS, 2003, p. 14). Para ele, a decadência da esfera pública é percebida pelo uso da publicidade com fins manipulativos, enquanto a publicidade crítica movimenta a comunicação pública e "indica o grau de democratização de uma sociedade industrial estruturada como social-democracia" (HABERMAS, 2003, p. 270). Assim, a formação de uma opinião pública crítica deve ser objetivo principal a ser alcançado pelo processo de democratização.

0 estabelecimento de um ambiente democrático fica então comprometido por esse cenário e, para Amorim e Guimarães (2013), isso ameaça 0 exercício da efetiva liberdade de expressão pelos cidadãos. Ao discutir a relação entre discurso e poder, Van Djik (2012) argumenta que o discurso pode atuar na reprodução do poder social, principalmente ao exercer controle sobre os outros discursos. Percebe esse tipo de ação sendo praticada pelos detentores do poder, tal como "o Estado, a polícia, a mídia ou uma empresa interessada na supressão da liberdade da escrita e da fala" (DJIK, 2012, p. 18).

0 desenvolvimento do setor de comunicações no Brasil é fruto de uma história marcada pela supremacia dos grupos privados de comunicação em relação à comunicação pública, o que Lima (2012, p. 129) denomina de "liberalismo antidemocrático". Desde o seu início, baseouse no modelo norte-americano de exploração da radiodifusão, priorizando a ocupação desse mercado pela iniciativa privada comercial (LIMA, 2011, p. 28). Além dessa característica, o setor de comunicações no Brasil é marcado pela existência de monopólios e de propriedade cruzada dos meios, o que, de acordo com Lima (2012, p. 99), gera uma redução no número de grupos proprietários controladores da grande mídia e, por conseguinte, impossibilitam a "pluralidade e a diversidade" nos meios.

Em termos legais, esse contexto que privilegia a atividade privada instaurou no Brasil um setor de comunicações ausente de regulações, já que estas poderiam vir a limitar a lucratividade das empresas de mídia. Lima (2011) denomina este cenário como "no law", em que a pequena legislação existente não foi normatizada pelo Congresso Nacional ou não é cumprida.

Entendendo o cenário brasileiro como marcado pela concentração midiática, faz-se fundamental compreender a relação intrínseca de dependência 
entre radiodifusores, diretores de portais, jornais e revistas, empresários de publicidade e anunciantes, que atuam em parceria no sentido de garantir sua hegemonia, calcada tanto no interesse privado por lucratividade quanto no propósito de impor suas ideias políticas, sociais e econômicas como dominantes.

\section{Liberdade de expressão comercial: a síntese ideológica da autorregulamentação}

De acordo com o material coletado para esta pesquisa, o primeiro registro de uso do termo associado a uma ação do Conar foi durante a realização do $14^{0}$ Fórum Internacional sobre Liberdade de Expressão Comercial, em 1994, ocorrido em meio aos debates sobre a revisão constitucional. Segundo o site da International Advertising Association (IAA), o discurso da liberdade de expressão comercial aparece como tendência a partir da década de 1990, quando a entidade aponta que surgiram várias iniciativas que ameaçavam a livre iniciativa no mundo todo.

Segundo Rafael Sampaio ${ }^{10}$, a adoção da ideia de "liberdade de expressão comercial" pelo setor publicitário brasileiro tem influência norteamericana e passa a ser utilizada no país de maneira mais recorrente a partir da discussão em relação à proibição da publicidade de cigarros. Conforme ele, "ninguém pensava nisso, hoje é uma coisa que no mundo inteiro se fala".

A síntese argumentativa que concebeu o conceito de "liberdade de expressão comercial" foi fruto de uma sofisticação discursiva, a qual aliou a defesa da autorregulamentação, vinculando o "discurso gerencial" e econômico ao discurso em defesa das liberdades, construindo, assim, a ideia de interesse geral como prioritária em relação ao interesse privado do setor que antes se sobressaía.

Roger Shiner (2003) denomina esse discurso de "comercial expression doctrine" (doutrina da expressão comercial) e assinala que a sua tese central sustenta-se na ideia de que a "expressão comercial" deve ser protegida constitucionalmente da mesma maneira que formas de expressão políticas e religiosas o são. Ou seja, a propaganda comercial deve ser entendida como um modo de expressão como outra qualquer que promove a "autonomia individual" e a "autorrealização".

0 autor identifica esta doutrina como uma tentativa de evitar que os governos desenvolvam novas medidas regulatórias. Assim, com a extensão constitucional da proteção da liberdade de expressão às empresas, estas ficariam resguardadas dessas interferências. Tudo isto em um contexto marcado por uma supremacia política e econômica das corporações (SHINER, 
2003, p. 03), em que estas são entendidas como as "principais promotoras do bem-estar dos cidadãos num sistema econômico de livre iniciativa" (SHINER, 2003, p. 09).

De acordo com Shiner (2003), a visão "libertarianista" norte-americana fundamenta o discurso que se opõe a qualquer tipo de intervenção do Estado no funcionamento dos mercados. Segundo Amorim e Guimarães (2013), essa visão defende 0 "livre mercado de ideias" que seria, pois, "imune à regulação da democracia". 0 Estado é visto como único agente limitador da liberdade, enquanto as mídias privadas são vistas como promotoras da liberdade. Dessa forma, as grandes empresas são definidas como "titulares de direitos, como se fossem cidadãos individuais" (AMORIM; GUIMARÃES, 2013, p. 64).

Com base em Cram (2006), Amorim e Guimarães (2013, p. 74) discutem a diferença entre a visão libertarianista e a visão do republicanismo cívico em relação à regulação da publicidade é justamente a assimilação da liberdade da publicidade à liberdade de expressão pela primeira, enquanto a segunda propõe uma "regulação estrita" e diferencia a liberdade de publicidade e liberdade de expressão.

Como contraponto à visão libertarianista, Shiner (2003) apresenta a visão "anticorporativista", a qual coloca as empresas no centro da crítica do sistema, compreendendo-as como corruptoras da democracia, manipuladoras dos trabalhadores e cidadãos e causadoras das desigualdades entre ricos e pobres (SHINER, 2003, p. 10). Vale pontuar os raciocínios que amparam essa "doutrina da expressão comercial" de acordo com Shiner (2003, p. 270): a regulação governamental obstrui o livre fluxo de informações comerciais; este é bom tanto para 0 indivíduo como para a sociedade, por isso sua interrupção é ruim. Desse modo, a regulação governamental deve ser abolida.

Para os empresários, reivindicar o "direito corporativo" e exigir a proteção constitucional à expressão comercial é, assim, uma forma de proteger as empresas e os cidadãos. A estratégia das corporações baseia-se, então, em "tomar emprestado" (borrow) os direitos de autonomia dos indivíduos para as empresas, algo muito próximo ao que Lima (2012) analisou como uma apropriação dos empresários de comunicação quando igualam a liberdade de imprensa à liberdade de expressão.

Essas apropriações são analisadas por Amorim e Guimarães (2013) como "graves fenômenos de corrupção da opinião pública”, e os autores compreendem esse debate como central nas discussões contemporâneas sobre a comunicação midiatizada: "Os diferentes entendimentos acerca da ideia de liberdade de expressão estão no centro de vastas e ásperas polêmicas contemporâneas sobre as relações entre democracia e meios de comunicaçãa" (AMORIM; GUIMARÃES, 2013, p. 17).

Identificam ainda que, antes, 0 Estado e a censura que este exercia eram vistos como grandes entraves 
para a formação da opinião pública livre, mas hoje os conglomerados de comunicação e sua "mercantilização e concentração" são o principal obstáculo para a construção de uma opinião pública democrática. Para Venício Lima (2012, p. 85), a sociedade civil organizada não quer ser tutelada "nem pelo Estado, nem pelo mercado". 0 autor reitera que a estratégia do mercado de apresentar seus interesses como os de toda a sociedade desconsidera os avanços das últimas décadas em relação à conscientização do "cidadão consumidor", que não aceita a hipótese de que "interesses puramente comerciais" são os mesmos seus.

Nesse mesmo sentido, Harvey (2011) defende que tanto Estado quanto os detentores do capital estão "na defensiva" diante das crescentes críticas: "suas alegações de que agem para o benefício de todos estão criticamente desacreditadas, assim como suas alegações de que são os benfeitores da humanidade como agentes da acumulação do capital baseada no mercado" (HARVEY, 2011, p. 148).

Percebe-se, portanto, por parte do discurso do setor em defesa de autorregulamentação, a recorrência ao interesse privado como interesse geral ou, como disseram Amorim e Guimarães (2013, p. 15), "a sobreposição e a legitimação de interesses e opiniões particularistas como se fossem publicamente majoritários ou de sentido universalista".

0 trabalho desenvolvido por Guimarães e Amorim (2013) nos oferece também a chance de compreender o debate em torno do conceito de liberdade de expressão, percebendo que esse termo não é "axiologicamente neutro", e compõe, pois, visões de mundo e "paradigmas variados de justiça, assim como de Estado e de relação entre Estado e sociedade civil, política e economia, vida pública e vida privada etc." (p. 22).

Para Lima (2013), os grandes grupos de mídia construíram uma "significação dominante", que se define pelo maniqueísmo entre liberdade (liberdade de expressão) e censura estatal (regulação). "Como os grupos de mídia (ainda) têm o poder de construir e 'enquadrar' a agenda 'pública', eles se apresentam como os grandes defensores da liberdade e da liberdade de expressão, em particular" (LIMA, 2013, p. 11).

\section{Conar e a defesa da liberdade de expressão comercial}

Diferentemente das outras organizações do setor publicitário, que, de forma declarada em suas missões e documentos, dizem atuar na defesa de interesses corporativos, 0 Conar adota um discurso ambíguo, o qual busca tanto contemplar os interesses da indústria da propaganda como vincular suas ações à defesa de direitos sociais, como a "liberdade de expressão". Em texto disponível em seu site, há a afirmação de que a missão do Conselho é "impedir que a publicidade enganosa ou abusiva cause constrangimento ao consumidor ou a empresas e defender a liberdade de expressão 
comercial"11. 0 Conar se define ainda como uma organização não governamental, "que visa promover a liberdade de expressão publicitária e defender as prerrogativas constitucionais da propaganda comercial". Ou seja, expõe o seu interesse como sendo geral, evitando a imagem de uma entidade corporativa.

0 atual discurso em defesa da liberdade de expressão comercial baseia-se, como foi visto, em uma visão de mundo que tem raízes tanto no liberalismo econômico como em sua versão mais contemporânea: o neoliberalismo. De acordo com o mapeamento realizado nesta pesquisa, as posições discursivas tomadas pelo Conar ao longo da sua história têm origem mais recorrente em três matrizes discursivas: a defesa das liberdades, a defesa da atividade publicitária e a defesa da autorregulamentação.

A primeira destas baseia-se na defesa das liberdades por meio de uma visão neoliberal, que defende como princípios absolutos a liberdade da iniciativa privada, a liberdade de escolha, a liberdade de anunciar, a liberdade de imprensa, a livre circulação de informações e, como síntese, a liberdade de expressão comercial. Articula esses princípios a um discurso de cunho jurídicolegal e propõe que a autorregulamentação assegura a liberdade dos envolvidos na atividade publicitária e as liberdades da sociedade em geral, como também vê as iniciativas regulatórias extramercado como inconstitucionais, ilegais ou causadoras de uma "insegurança jurídica", por serem elaboradas por pessoas externas ao setor e que, portanto, não têm conhecimento técnico da atividade. Além disso, reivindica a publicidade como uma das expressões protegidas constitucionalmente no artigo da Carta Magna que define a liberdade de expressão como "atividade intelectual, artística, científica e de comunicação, independentemente de censura ou licença".

A segunda matriz diz respeito à justificação da autodisciplina do setor a partir da defesa da atividade publicitária, defendendo-a como essencial para o desenvolvimento econômico e para a disseminação de informações fundamentais para 0 consumidor. Ela ressalta 0 valor cultural da publicidade, considerando-a como fonte de informação e como atividade que propicia a sustentação financeira de diversos veículos de comunicação, tendo, pois, um papel fundamental para a realização da liberdade de imprensa. Essa mesma matriz discursiva vê a informação publicitária como essencial, inclusive, para divulgar os malefícios dos produtos e defende que a nocividade de determinado produto não pode ser atribuída à propaganda e que, logo, deve ser assegurada a divulgação de qualquer produto lícito liberado para comercialização. Como visto no decorrer do texto, a publicidade também foi defendida como atividade econômica desde 0 seu advento no Brasil como setor. Percebida em 
um primeiro momento como passaporte para 0 progresso e para a modernidade e como melhor forma para promover o escoamento e a circulação dos produtos industriais, passa a ser justificada como parte de um setor econômico importante, que gera empregos e participa de mais de $2,5 \%$ do PIB brasileiro ${ }^{12}$. A interferência nessa atividade é entendida, a partir desse ponto de vista, como uma forma de desestabilizar um importante segmento de mercado.

A terceira matriz discursiva consiste em um trabalho contínuo de defesa da autorregulamentação através de uma visão corporativa e de autoelogios em relação aos aspectos institucionais do Conar. Esse discurso apoia-se no objetivo de consolidar a imagem do Conar como instituição legítima para tratar da regulação da publicidade brasileira por meio das suas campanhas de divulgação, publicações e posicionamentos públicos. Entre os principais argumentos que sustentam essa posição, estão as ideias de 1) voluntarismo: tanto pelo fato de todos os membros do Conselho serem voluntários, como pela vontade do próprio mercado instituir um mecanismo de autorregulamentação - embora tenhamos analisado também que há o interesse direto do mercado em evitar a regulação estatal -; 2) maturidade: 0 Conselho nasce em um período em que a publicidade brasileira começa a ter projeção internacional, passa a atuar dentro de parâmetros profissionais mais rígidos, e as entidades corporativas da área já completavam décadas desde a sua fundação. Por isso, tal progresso é proclamado como fruto de um setor capaz de se autorregular; 3) autonomia: 0 setor contrapõe-se à "tutela estatal" e ressalta a independência em elaborar suas próprias regras; 4) pioneirismo: diferentemente de outras áreas da comunicação e setores empresariais, o setor publicitário tem 0 seu próprio Código de autorregulamentação. Este mesmo documento trata também de questões não abordadas em outros mecanismos legais, e suas revisões permitem que o mesmo torne-se cada vez mais sintonizado com os anseios sociais - embora as atualizações ao Código tenham sido identificadas nessa análise como resultantes mais da posição reativa às iniciativas regulatórias e menos de uma atitude pioneira -; 5) não judicialização: 0 Conar proporcionaria 0 acordo entre as partes, evitando a interferência do Estado e punições mais rígidas como as previstas no CDC (Código de Defesa do Consumidor); 6) eficiência: o Conar propaga-se como meio mais rápido para o julgamento das denúncias feitas por consumidores, agências e anunciantes, em um contraponto a uma visão dos órgãos estatais como permeados pela burocracia e pela lentidão; 7) representação da sociedade civil: 0 fato de 0 Conselho contar com representantes da sociedade civil indicados pela sua diretoria é ressaltado como significativo para a isenção 
dos julgamentos - na análise, percebeu-se que essa representação é minoritária (cerca de $25 \%)$ se comparada com o número de membros diretamente vinculados à atividade publicitária -; 8) poucas reclamações em relação à publicidade: mais recentemente, essa estratégia tem sido propagada a partir do uso de dados do Procon que afirmam que menos de 1,5\% das reclamações recebidas pelo órgão é relacionada à propaganda. Assim, o Conselho entende que não se justifica tanta preocupação dos órgãos estatais e das entidades consumeristas em regular a publicidade de forma mais rígida.

A resistência do setor publicitário em se adequar aos novos debates relativos à regulação da publicidade mostra que o mesmo setor tem clareza da questão central que essa disputa impõe: a subordinação dos interesses privados em relação aos interesses públicos. Algo que, mais do que ameaçar 0 setor publicitário especificamente, pode abrir caminhos para uma nova visão sobre o papel das empresas na sociedade contemporânea.

\section{Referências}

ALMEIDA, Maria Hermínia Tavares de. Além do Corporativismo: Interesses Organizados e Democratização. In: SOLA, Lourdes, PAULANI, Leda (Orgs.). Lições da Década de 80. São Paulo e Genebra: Editora da Universidade de São Paulo e UNRISD, 1995.

AMORIM, Ana Paola. 0 desafio do encontro da opinião pública democrática com a soberania popular: uma defesa republicana do direito de pronunciar a liberdade. Mediação, Belo Horizonte, v. 15, n. 17, jul./ dez. de 2013.
AMORIM, Ana Paola; GUIMARÃES, J. R. A corrupção da opinião pública: uma defesa republicana da liberdade de expressão. $1^{\mathrm{a}}$ ed. São Paulo: Boitempo Editorial, 2013. v. 1.

BEZERRA, Glícia Maria Pontes. Liberdade de expressão comercial: autorregulamentação como estratégia corporativa do setor publicitário. Tese de doutorado. Recife: UFPE, 2015.

\section{BLOTTA, Vítor Souza Lima. 0 direito da}

comunicação: reconstrução dos princípios normativos da esfera pública política a partir do pensamento de Jürgen Habermas. 2012. Tese (Doutorado em Filosofia e Teoria Geral do Direito) - Faculdade de Direito, Universidade de São Paulo, São Paulo, 2012.

COMPARAT0, Fábio K. A democratização dos meios de comunicação de massa. Revista USP, São Paulo, n. 48, p. 6-17, 2000.

CORREAA, Roberto (Org.). Movimento Nacional pela Livre Iniciativa: uma contribuição da publicidade à democracia brasileira. São Paulo: Bossa Nova, 2008.

COURTINE, J. Analyse du discours politique.

Langages, Paris, n. 62, 1981.

CRAM, Ian. Contested Words: Legal Restrictions on Freedom of Speech in Liberal Democracies. Ashgate: Hampshire, 2006.

DAGNINO, E. Confluência perversa, deslocamentos de sentido, crise discursiva. In: Alejandro Grimson. (Org.). La cultura en las crisis latinoamericanas. Buenos Aires: CLACSO, 2004b, p. 195-216.

DJIK, Van. Discurso e Poder. São Paulo: Contexto, 2012. FIORI, José Luís. 0 vôo da coruja: para reler 0 desenvolvimentismo brasileiro. Rio de Janeiro: Record, 2003.

HABERMAS, Jürgen. Mudança estrutural da esfera pública. Rio de Janeiro: Tempo Brasileiro, 2003.

HARVEY, David. 0 enigma do capital e as crises do 
capitalismo. São Paulo: Boitempo Editorial, 2011.

JAMESON, Fredric. A virada cultural: reflexões

sobre o pós-modernismo. Rio de Janeiro: Civilização

Brasileira, 2006.

KIRKPATRICK, Jerry. Em defesa da propaganda:

argumentos a partir da razão, do egoísmo ético e

do capitalismo laissez-faire. São Paulo: Geração

Editorial, 1997.

LIMA, Venício. Regulação das Comunicações:

História, poder e Direitos. São Paulo: Paulus, 2011.

Liberdade de Expressão vs Liberdade da

Imprensa. $2^{\mathrm{a}}$ ed. São Paulo: Publisher Brasil, 2012.

Prefácio. In: AMORIM, Ana Paola;

GUIMARÃES, J. R. A corrupção da opinião pública:

uma defesa republicana da liberdade de expressão. 1.

ed. São Paulo: Boitempo Editorial, 2013. v. 1.

SHINER, Roger. Freedom of Commercial Expression.

Nova Iorque: Oxford University Press, 2003. 


\section{Freedom of comercial expression as corporate estrategy of Brazilian advertising industry}

\section{Abstract}

The purpose of this paper is to investigate the origins of the concept "freedom of commercial expression" and analyze how this came to be adopted by the Brazilian advertising industry from the $90 \mathrm{~s}$. The research was conducted from the collection of documents and interviews that helped in the historical reconstruction of the sector entities, as well as disputes about the regulation of advertising, which allowed the perception of discursive positions contrary to regulatory initiatives that increase control of advertising in Brazil. The analysis found that the current discourse in defense of freedom of commercial expression is a synthesis based on three arguments: defense of freedom, defense of self-regulation and defense of advertising activity.

\section{Keywords}

Freedom of expression. Advertising.

Regulation. Discourse.

\section{La libertad de expresión comercial como estrategia corporativa del sector publicitario brasileño}

\section{Resumen}

El objetivo de este artículo es investigar los orígenes del concepto de "libertad de expresión comercial" y analizar cómo él fue adoptado por el sector publicitario brasileño a partir de los años 90. La investigación se llevó a cabo a partir de la recopilación de documentos y entrevistas que ayudaron en la reconstrucción del histórico de las entidades del sector, así como las disputas sobre la reglamentación de la publicidad, lo que permitió la percepción de las posiciones discursivas contrarias a las iniciativas regulatorias dirigidas a un mayor control de la publicidad en el país. El análisis constató que el actual discurso en defensa de la libertad de expresión comercial es una síntesis basada en tres matrices: defensa de la libertad, defensa de la autorregulación y defensa de la actividad publicitaria.

\section{Palabras clave}

Libertad de expresión. Publicidad.

Reglamentación. Discurso. 


\section{Expediente}

A revista E-Compós é a publicação científica em formato eletrônico da Associação Nacional dos Programas de Pós-Graduação em Comunicação (Compós). Lançada em 2004, tem como principal finalidade difundir a produção acadêmica de pesquisadores da área de Comunicação, inseridos em instituições do Brasil e do exterior.

\section{E-COMPÓS I www.e-compos.org.br I E-ISSN 1808-2599}

Revista da Associação Nacional dos Programas de Pós-Graduação em Comunicação.

Brasília, v.18, n.3, set./dez. 2015.

A identificação das edições, a partir de 2008, passa a ser volume anual com três números.

Indexada por Latindex I www.latindex.unam.mx

\section{CONSELHO EDITORIAL}

Alexandre Farbiarz, Universidade Federal Fluminense, Brasil Alexandre Rocha da Silva, Universidade Federal do Rio Grande do Sul, Brasil Ana Carolina Damboriarena Escosteguy, Pontifícia Universidade Católica do Rio Grande do Sul, Brasil

Ana Carolina Rocha Pessôa Temer, Universidade Federal de Goiás, Brasil Ana Regina Barros Rego Leal, Universidade Federal do Piauí, Brasil Andrea França, Pontifícia Universidade Católica do Rio de Janeiro, Brasil André Luiz Martins Lemos, Universidade Federal da Bahia, Brasil Antonio Carlos Hohlfeldt, Pontifícia Universidade Católica do Rio Grande do Sul, Brasil

Arthur Ituassu, Pontifícia Universidade Católica do Rio de Janeiro, Brasil Álvaro Larangeira, Universidade Tuiuti do Paraná, Brasil Ângela Freire Prysthon, Universidade Federal de Pernambuco, Brasil César Geraldo Guimarães, Universidade Federal de Minas Gerais, Brasil Cláudio Novaes Pinto Coelho, Faculdade Cásper Líbero, Brasil Daisi Irmgard Vogel, Universidade Federal de Santa Catarina, Brasil Denize Correa Araujo, Universidade Tuiuti do Paraná, Brasil Eduardo Antonio de Jesus, Pontifícia Universidade Católica de Minas Gerais, Brasil

Daniela Zanetti, Universidade Federal do Espirito Santo, Brasil Eduardo Vicente, Universidade de São Paulo, Brasil Elizabeth Moraes Gonçalves, Universidade Metodista de São Paulo, Brasil Erick Felinto de Oliveira, Universidade do Estado do Rio de Janeiro, Brasil Francisco Elinaldo Teixeira, Universidade Estadual de Campinas, Brasil Francisco Paulo Jamil Almeida Marques, Universidade Federal do Paraná, Brasil

Gabriela Reinaldo, Universidade Federal do Ceará, Brasil Goiamérico Felício Carneiro Santos, Universidade Federal de Goiás, Brasil Gustavo Daudt Fischer, Universidade do Vale do Rio dos Sinos, Brasil Herom Vargas, Universidade Municipal de São Caetano do Sul, Brasil Itania Maria Mota Gomes, Universidade Federal da Bahia, Brasil
Janice Caiafa, Universidade Federal do Rio de Janeiro, Brasil Jiani Adriana Bonin, Universidade do Vale do Rio dos Sinos, Brasil José Afonso da Silva Junior, Universidade Federal de Pernambuco, Brasil José Luiz Aidar Prado, Pontifícia Universidade Católica de São Paulo, Brasil Juçara Gorski Brittes, Universidade Federal de Ouro Preto, Brasil Kati Caetano, Universidade Tuiuti do Paraná, Brasil

Lilian Cristina Monteiro França, Universidade Federal de Sergipe, Brasil Liziane Soares Guazina, Universidade de Brasília, Brasil Luíza Mônica Assis da Silva, Universidade de Caxias do Sul, Brasil Luciana Miranda Costa, Universidade Federal do Pará, Brasil Malena Segura Contrera, Universidade Paulista, Brasil Maria Ogécia Drigo, Universidade de Sorocaba, Brasil Maria Ataide Malcher, Universidade Federal do Pará, Brasil Marcia Tondato, Escola Superior de Propaganda e Marketing, Brasil Marcel Vieira Barreto Silva, Universidade Federal da Paraíba, Brasil Maria Clotilde Perez Rodrigues, Universidade de São Paulo, Brasil Maria das Graças Pinto Coelho, Universidade Federal do Rio Grande do Norte, Brasil

Mauricio Ribeiro da Silva, Universidade Paulista, Brasil

Mauro de Souza Ventura, Universidade Estadual Paulista, Brasil Márcio Souza Gonçalves, Universidade do Estado do Rio de Janeiro, Brasil Micael Maiolino Herschmann, Universidade Federal do Rio de Janeiro, Brasil Mirna Feitoza Pereira, Universidade Federal do Amazonas, Brasil Nísia Martins Rosario, Universidade Federal do Rio Grande do Sul, Brasil Potiguara Mendes Silveira Jr, Universidade Federal de Juiz de Fora, Brasil Regiane Regina Ribeiro, Universidade Federal do Paraná, Brasil Rogério Ferraraz, Universidade Anhembi Morumbi, Brasil Rose Melo Rocha, Escola Superior de Propaganda e Marketing, Brasil Rozinaldo Antonio Miani, Universidade Estadual de Londrina, Brasil Sérgio Luiz Gadini, Universidade Estadual de Ponta Grossa, Brasil Simone Maria Andrade Pereira de Sá, Universidade Federal Fluminense, Brasil Veneza Mayora Ronsini, Universidade Federal de Santa Maria, Brasil Walmir Albuquerque Barbosa, Universidade Federal do Amazonas, Brasil

\section{COMISSÃO EDITORIAL}

Cristiane Freitas Gutfreind

Pontifícia Universidade Católica do Rio Grande do Sul, Brasil

Irene Machado

Universidade de São Paulo, Brasil

\section{CONSULTORES AD HOC}

Claudia Peixoto de Moura, Pontificia Universidade Católica do Rio Grande do Sul, Brasil Francisco Rüdiger, Pontifícia Universidade Católica do Rio Grande do Sul, Brasil Juremir Machado da Silva, Pontifícia Universidade Católica do Rio Grande do Sul, Brasil Maria Aparecida Baccega, Universidade de São Paulo, Brasil

Roberto Tietzmann, Pontifícia Universidade Católica do Rio Grande do Sul, Brasil

\section{EQUIPE TÉCNICA}

ASSISTENTE EDITORIAL I Márcio Zanetti Negrini

REVISÃO DE TEXTOS I Press Revisão

EDITORAÇÃO ELETRÔNICA I Roka Estúdio

CONTATO I revistaecompos@gmail.com
COMPÓS I www.compos.org.br

Associação Nacional dos Programas de Pós-Graduação em Comunicação

Presidente

Edson Fernando Dalmonte

Programa de Pós-Graduação em Comunicação

e Cultura Contemporânea - UFBA

edsondalmonte@uol.com.br

Vice-presidente

Cristiane Freitas Gutfreind

Programa de Pós-Graduação em Comunicação Social - PUC-RS cristianefreitas@pucrs.br

Secretário-Geral

Rogério Ferraraz

Programa de Pós-Graduação em Comunicação

Universidade Anhembi Morumbi

rogerioferraraz@anhembimorumbi.edu.br 